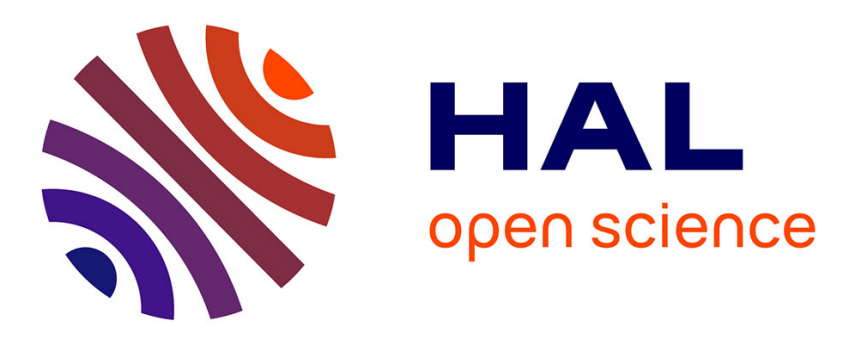

\title{
Prescription of antiepileptics and the risk of road traffic crash.
}

Ludivine Orriols, Alexandra Foubert-Samier, Blandine Gadegbeku, Bernard Delorme, Aurore Tricotel, Pierre Philip, Nicholas Moore, Emmanuelle Lagarde

\section{- To cite this version:}

Ludivine Orriols, Alexandra Foubert-Samier, Blandine Gadegbeku, Bernard Delorme, Aurore Tricotel, et al.. Prescription of antiepileptics and the risk of road traffic crash.. Journal of Clinical Pharmacology, 2013, 53 (3), pp.339-44. 10.1002/jcph.10 . hal-00937083

\section{HAL Id: hal-00937083 https://hal.science/hal-00937083}

Submitted on 27 Jan 2014

HAL is a multi-disciplinary open access archive for the deposit and dissemination of scientific research documents, whether they are published or not. The documents may come from teaching and research institutions in France or abroad, or from public or private research centers.
L'archive ouverte pluridisciplinaire HAL, est destinée au dépôt et à la diffusion de documents scientifiques de niveau recherche, publiés ou non, émanant des établissements d'enseignement et de recherche français ou étrangers, des laboratoires publics ou privés. 


\section{Prescription of antiepileptics and the risk of road traffic crash}

Ludivine Orriols, PhD, ${ }^{1,2}$ Alexandra Foubert-Samier, MD, ${ }^{1,3}$ Blandine Gadegbeku, MSc, 4,5,6 Bernard Delorme, MD, PhD, ${ }^{7}$ Aurore Tricotel, MSc, ${ }^{7}$ Pierre Philip, MD, PhD, ${ }^{8}$ Nicholas Moore, $\mathrm{MD}, \mathrm{PhD}^{9}$ and Emmanuel Lagarde, $\mathrm{PhD},{ }^{1,2}$ on behalf of the CESIR research group

${ }^{1}$ Univ. Bordeaux, ISPED, Centre INSERM U897-Epidemiologie-Biostatistique, F-33000 Bordeaux, France

${ }^{2}$ INSERM, Equipe Prévention et prise en charge des traumatismes, ISPED, Centre INSERM U897-Epidemiologie-Biostatistique, F-33000 Bordeaux, France

${ }^{3}$ INSERM, Equipe Epidémiologie et neuropsychologie du vieillissement cérébral, ISPED, Centre INSERM U897-Epidemiologie-Biostatistique, F-33000 Bordeaux, France

${ }^{4}$ Université de Lyon, F-69000, Lyon, France

${ }^{5}$ IFSTTAR, UMR T 9405, UMRESTTE, F-69500, Bron, France

${ }^{6}$ Université Lyon 1, UMRESTTE, F-69000, Lyon, France

${ }^{7}$ Service de l'Evaluation de la Surveillance du Risque et de l’Information sur le Médicament, Agence Française de Sécurité Sanitaire des Produits de Santé (AFSSAPS), Saint-Denis,

France

${ }^{8}$ USR CNRS SANPSY 3413, Université Bordeaux Segalen, Bordeaux, France

${ }^{9}$ INSERM U657, CIC-P0005, Département de Pharmacologie, Université Bordeaux Segalen, Bordeaux, France

Disclosure of conflicts of interest: None of the authors has any conflict of interest to disclose.

Corresponding author/reprints: Ludivine Orriols, ludivine.orriols@isped.u-bordeaux2.fr

Equipe prévention et prise en charge des traumatismes

Centre de recherche INSERM U897 "Epidémiologie et Biostatistiques"

Université Bordeaux Segalen, Case 11, 146 rue Léo Saignat

33076 Bordeaux Cedex, France

Tel/Fax: +(33) 557571504

Key words: road traffic crashes, antiepileptics, epidemiology

Word count: introduction: 317, discussion: 880

Tables: 2

References: 23 


\section{ABSTRACT}

Objective: Studies assessing the impact of epilepsy and its medication on the risk of road traffic crashes have shown inconsistent results. The aim in this study was to assess this risk using French databases.

Methods: Data from three French national databases were extracted and matched: the national health care insurance database, police reports and the national police database of injurious crashes. Only antiepileptics prescribed predominantly in epilepsy were studied (phenobarbital, phenytoin, ethosuximide, valproic acid, vigabatrin, tiagabin, levitiracetam, zonisamide and lacosamide). A case-control analysis comparing responsible and non-responsible drivers and a case-crossover analysis were performed.

Results: 72,685 drivers involved in an injurious crash in France between July 2005 and May 2008, were included. Drivers exposed to prescribed antiepileptic medicines $(n=251)$ had an increased risk of being responsible for a crash (OR 1.74 [1.29-2.34]). The association was also significant for the most severe epileptic patients ( $n=99$; OR=2.20 [1.31-3.69]). Casecrossover analysis found no association between crash risk and treatment prescription.

Conclusion: Patients with prescription of antiepileptic drugs should be cautioned about their potential risk of road traffic crash. This risk is however more likely to be related to seizures that to the effect of antiepileptic medicines. 


\section{INTRODUCTION}

The impact of epilepsy on the risk of road traffic crashes is still debated. Some studies have found an increased risk of road traffic crash in drivers with epilepsy, ${ }^{1,2}$ another one showed an increased risk of more severe crashes only. ${ }^{3}$ However, in a recent cohort study, patients with epilepsy were not at increased risk of experiencing a road traffic crash. ${ }^{4}$

Antiepileptic medicines are used to treat general or partial seizures and to prevent the risk of relapse, but also in numerous other diseases such as bipolar disorders, ${ }^{5}$ social phobia and generalised anxiety disorder. ${ }^{6}$ Most antiepileptic medicines have however central side effects that may impair driving ability, such as drowsiness, confusion, dizziness, and visual disturbances. The first generation of antiepileptic medicines includes phenobarbital and phenytoin, which have gradually been supplanted by the second generation, carbamazepine and valproate. The new antiepileptic medicines (or third generation) appeared on the market in the 1990’s (e.g. lamotrigine, vigabatrin, gabapentin...). Finally, some benzodiazepines, such as clonazepam, are used in the treatment of epilepsy for their anticonvulsant properties. Experimental studies show that phenobarbital seems to have the most deleterious effects on behaviour and cognition. ${ }^{7}$ Available data on the third-generation drugs suggest a more favourable profile than older treatments, although differences between them remain to be explored. ${ }^{8,9}$ As with other benzodiazepines, clonazepam is associated with a high rate of drowsiness and decreased attention. ${ }^{7}$

In spite of these potential effects on driving skills, available data suggest antiepileptic treatment to favour road safety by controlling the risk of seizure. In a retrospective cohort study, Hansotia and Broste found that the lack of antiepileptic treatment increased the risk of crashes among drivers who had a history of seizures. ${ }^{10}$ In a case-control study, changes in antiepileptic treatment (antiepileptic medicines being reduced or switched) decreased the risk of road traffic crashes due to seizures. ${ }^{11}$ 
The aim of this study was to assess the risk of road traffic crashes among drivers with prescribed antiepileptic treatment.

\section{METHODS}

Data from three French nationwide databases were matched: the national health care insurance database, police reports, and the national police database of injurious crashes. Drivers were included in the study on the basis of their national ID number, extracted from police reports by an automatic procedure. The ID was used to link drivers to medicine reimbursement data around the date of the crash. Police reports were matched to records in the national police database of injury-related crashes, using a probabilistic linkage method. ${ }^{12}$

\section{Data sources}

National police database of injurious crashes. Police personnel collect details about injurious road traffic crashes and store all information about the crash, vehicles, and persons involved in this database. They also conduct investigations from hospital records about the severity of the driver's injuries: unhurt, slightly injured, seriously injured (hospitalised $>24$ h), or killed (died within 30 days following the crash). All drivers involved in an injurious road traffic crash are required to be tested for the presence of alcohol, using a breath test. If this test is positive ( $\geq 0.5 \mathrm{~g} / \mathrm{l})$, the driver refuses the test, or the severity of the crash makes it impossible to administer the test, then the blood alcohol concentration is measured. If the breath test is negative, the driver is registered as not being under the influence of alcohol.

Police reports. Police personnel are required to fill out a report for each injurious traffic crashes occurring in the country. Police reports are scanned and archived as image files. For approximately $28 \%$ of drivers involved, the national ID number is recorded in the report. All the 210,818 available police reports in France from July 2005 to May 2008 were gathered. 
Health care insurance database. The national health care insurance system database covers the entire population of France (64 million people in 2008). A record is added each time a reimbursed prescription medicine is dispensed to an outpatient at a pharmacy, including national ID number, date of dispensing, and the seven-digit code that identifies medicines. Data on long-term chronic diseases are also registered in this database, with the ICD-10 code (International Classification of Diseases, Tenth Revision) as well as the start and end dates of the disease. In France, patients are fully reimbursed for health care expenses related to 30 recognized long-term chronic diseases.

\section{Epilepsy}

In order to allocate epileptic patients to the administrative status of "long-term chronic disease”, several severity criteria are investigated: impact on cognition, on family or on professional life, frequency and type of seizures, resistance to treatments or side effects linked to treatment. Thus, we used this status as a proxy for epilepsy severity, indicating patients with the most severe symptoms. ${ }^{13}$ In France, this represents around $10 \%$ of epileptic patients (Haute Autorité de Santé, 2007). Patients were considered as suffering from severe epilepsy on the day of the crash if the date of the crash was included between the start and end dates of the ICD-10 G40 code long-term chronic disease.

\section{Medicines and exposure periods}

Antiepileptics. In order to study antiepileptics predominantly prescribed in epilepsy and not in other conditions, we used data from a survey on medicine prescriptions in France (EPPM, IMS Health) that describes indications for each medicine. We included in the analyses medicines used in more than 75\% of cases in epilepsy. These antiepileptic medicines were further studied according to the three following groups: first generation (phenobarbital and phenytoin), second generation (valproic acid and ethosuximide) and third generation 
(vigabatrin, tiagabin, levitiracetam, zonisamide and lacosamide). Patients receiving more than one single antiepileptic drug were defined as under polytherapy.

In France, no more than 30 days’ worth of treatment with antiepileptics may be dispensed by pharmacies, so 30 days of exposure were attributed following each dispensing.

Concomitant exposure. In France, a classification of medicines that potentially affect driving abilities have classified into four levels of risk (Castot and Delorme, 2009; Arrêté, 2008; Afssaps, 2009). ${ }^{14-16}$ Consequently, analyses were adjusted for the use of other medicines grouped according to this classification system.

Exposure was considered to have started the day after the drug was dispensed. In order to ensure that the medicines were not those prescribed as a treatment for injuries sustained in the crash, medicines dispensed on the day of the crash were not considered in the analysis.

\section{Analysis}

Inclusion of subjects. Subjects whose police report did not contain their national ID number were not included. We compared the included subjects with the non-included ones with respect to age, gender, severity of injury, vehicle type, location of the crash, the type of police personnel who filled in the police report, alcohol level, and responsibility status Descriptive analysis. Frequencies of exposures to antiepileptics were compared according to individual and crash characteristics in a multivariate logistic regression analysis. Responsibility analysis. The principle of responsibility analysis is to compare exposure probabilities on the day of the crash between the drivers deemed responsible for the crash (cases) and those not responsible (controls). Responsibility levels related to the crash were determined by a method adapted from Robertson and Drummer. ${ }^{17}$ This method, recently used in France using data from the national police database of fatal crashes, takes into account six factors likely to reduce driver responsibility: road, vehicle and driving conditions, type of 
crash, traffic rule obedience, and difficulty of task involved. A score is assigned to each driver for each of these factors, from 1 (favourable for driving) to 4 (not favourable for driving). ${ }^{18}$ The logistic regression model included terms for age, gender, socioeconomic category, month of the crash, time of the crash, location of the crash, type of vehicle, severity of injury, blood alcohol level, concomitant medications, long-term chronic diseases, and severe epilepsy. Case-crossover analysis. The case-crossover analysis consisted of a pair-matched analytical approach to compare exposure during a period immediately before the crash (case period) with exposure during an earlier period (control period) for the same subject. ${ }^{19}$ We compared antiepileptic exposure during the three months before the crash with antiepileptic exposure during an earlier three-month control period. Odds ratios were estimated by conditional logistic regression.

Data were analysed using the SAS $^{\circledR}$ statistical software package, version 9.0 (SAS Institute, Cary, NC).

This study was approved by the French Data Protection Authority.

\section{RESULTS}

Extraction and matching procedures led to the inclusion of 72,685 drivers who were involved in road traffic crashes (34,896 were responsible for causing the crash and 37,789 were not). These accounted for $18.5 \%$ of the 392,169 drivers registered in the national police database of injurious traffic crashes. The severity of injury was the main factor associated with the probability of being part of the study. The inclusion rate was approximately the same for responsible and non-responsible drivers (18.8\% and 18.3\%, respectively).

251 drivers (0.35\%) were exposed to at least one antiepileptic on the day of the crash. The multivariate descriptive analysis showed that exposure to antiepileptics was higher among men, drivers aged over 45 years and unemployed drivers. Antiepileptic exposure was more 
likely among drivers involved in single-vehicle crashes. Exposure to antiepileptic medicines was not associated with blood alcohol concentration (Table 1).

Multivariate responsibility analysis measured an odds ratio of 1.74 [1.29-2.34] for drivers exposed to antiepileptics. 99 drivers $(0.14 \%)$ were registered on the day of the crash as with ICD-10 G40 code long-term chronic disease. The odds ratio was 2.20 [1.31-3.69] for these drivers compared with all other drivers. Among these 99 drivers with severe epilepsy, 36 (36.4\%) had their last antiepileptic prescription at least 31 days before the crash suggesting they were not exposed to the medicine on the day of the crash. The odds ratio for responsible crash in this subsample was slightly the same as in the 63 drivers exposed to an antiepileptic on the day of the crash $(\mathrm{OR}=2.91$ [1.25- 6.77] and $\mathrm{OR}=2.02$ [1.01-4.04], respectively). Multivariate responsibility analysis showed a significant association between exposure to second and third generation of antiepileptics and responsibility (OR=2.15 [1.56-2.97] and $\mathrm{OR}=3.01$ [1.40-6.44], respectively) (Table 2).

The odds ratio was 1.67 [0.98-2.83] for drivers exposed to several antiepileptics on the day of the crash ( $\mathrm{n}=87)$ and 1.81 [1.27-2.57] for drivers under monotherapy $(\mathrm{n}=164)$, compared to non-users.

The case-crossover analysis found no association between the risk of crash and exposure to antiepileptics (OR=0.68 [0.42-1.10]).

\section{DISCUSSION}

The analysis of medicines dispensed to 72,685 drivers involved in injurious road traffic crashes in France between July 2005 and May 2008 found that drivers with prescribed antiepileptic medicines have an increased risk of being responsible for a crash (adjusted OR 1.74 [1.29-2.34]. Drivers with severe epilepsy had a two-fold increased responsibility risk $(\mathrm{OR}=2.20[1.31-3.69])$ 
The responsibility analysis lends real strength to the study because it allows for comparisons of cases and controls who share the characteristic of being drivers. In a previous study on the impact of illegal drug consumption, using the same national police database but limited to fatal collisions, ${ }^{18}$ the same method was used to determine responsibility and was approved by an expert evaluation of responsibility. ${ }^{18}$ The strong dose-effect relationship found in our study between alcohol level and responsibility is a further indirect validation of the method. Responsibility levels were computed independently of the use of alcohol and illicit drugs because of their potential interactions with medical drugs.

The results showed that drivers who had been severely injured were more likely to be included in the study than those who had sustained slight injuries or who had died. Injured drivers were more likely to be admitted to hospital, and therefore their health care numbers were more likely to be noted in police reports. Consequently, our study sample slightly overrepresented drivers who had been involved in more serious crashes.

In our study, severe epilepsy referred to a long-term chronic disease for which patients are fully reimbursed for health care expenses related to the disease. Patients who may benefit from this system are those suffering from resistant epilepsy and/or for whom the epileptic disease has an impact on their socio-professional life. In France, a renewable one-year temporary driving licence can be delivered to epileptic patients after advice from a medical commission.

A study showed that when a seizure arises while driving, 55\% of epileptic patients $\mathrm{crash}^{20} \mathrm{~A}$ retrospective case-control study found that patients who had seizure-free intervals of more than one year had a 93\% reduced odds for crashing compared with patients with shorter intervals. ${ }^{11}$ In a longitudinal study, 222 of 1,089 epileptic patients (20.4\%), followed up between 1965 and 1991, had a seizure at the wheel and this percentage was even higher in drivers who had at least one seizure a month (36.2\%). ${ }^{21}$ A literature review on medical risks 
in epilepsy concluded that frequent seizures are a risk factor for accidents resulting in injuries, and that seizure-related fatalities are much more important in chronic epilepsy than in newonset cases. ${ }^{22}$ It is thus likely that drivers suffering from severe epilepsy in our study represent chronic epileptic patients with more frequent seizures. However, no information on the number or frequency of seizures was available in our study. An accident analysis report showed that crashes due to seizures are more likely to involve a single vehicle. ${ }^{23} \mathrm{We}$ consistently observed that drivers under antiepileptic treatment were more frequently involved in single-vehicle crashes.

A study showed that $59.4 \%$ of the patients who had seizures at the wheel also suffered from psychological disorders. ${ }^{21}$ In a recent cohort study, comorbidities were significantly higher in those with epilepsy compared with those without epilepsy, including alcohol abuse, drug abuse, psychoses, depression or other neurologic disorders. ${ }^{4}$ Our analyses were adjusted for blood alcohol level, prescribed medicines used in anxiety and depression disorders and other long-term chronic diseases including some mental, behavioural and nervous system disorders. Exposure to medications was ascertained from computerised records of reimbursed prescriptions filled in at the pharmacy, avoiding any recall bias. We did not know whether the medicines were actually ingested and had no information on serum drug level. A retrospective cohort study conducted in the US showed that epilepsy patients without regular driver’s licences were characterised by more non-compliance with antiepileptic treatment. ${ }^{10}$ Another study showed that $20 \%$ of patients who had a crash during a seizure crashed immediately after missing an antiepileptic dose. ${ }^{11}$ Non compliance could not be explored in our study because exposure was estimated solely from dispensing data. Further studies should be designed to measure antiepileptic blood concentrations in patients involved in road traffic crashes. Our results showed no significant association for the first generation of antiepileptics. Nowadays, these medicines are less and less prescribed. Patients undergoing these treatments 
may thus be long-time users who do not need to switch for newer drugs as their epilepsy is well controlled. Patients using these drugs may thus be less likely to experience seizures at the wheel. The increased responsibility risk for users of second and third generation of antiepileptics is probably more related to epilepsy than to the medicines themselves. The difficulty in such studies is to disentangle the impact of the medical condition and of medication. The absence of an association between the risk of crash and treatment prescription in the case-crossover analysis indicates that there is no acute effect of the treatment, suggesting that the risk is linked to seizures and probably not due to medicines. This hypothesis is reinforced by the results showing that the odds ratio was approximately the same in the subgroup of drivers suffering from severe epilepsy and not exposed to an antiepileptic medicine on the day of the crash (OR=2.91 [1.25-6.77]) compared with exposed drivers (OR=2.02 [1.01-4.04]). In addition, in our study, patients under polypharmacy were not at increased risk of being responsible for a crash. Data reported from epidemiological studies, also suggests that the risk of crash is associated with the lack of treatment or changes in treatment (antiepileptic medicines being reduced or switched). ${ }^{10,11}$ Patients with prescription of antiepileptic drugs should however be cautioned about their potential risk of road traffic crash. 


\section{Acknowledgments}

We thank the CESIR research group for its collaborative support: in addition to the authors, Marta Avalos (Inserm U897, Université Bordeaux 2), Fabienne Bazin (Inserm U657), Sylvie Blazejewski (CIC 0005, Bordeaux), Benjamin Contrand (Inserm U897), Geneviève Durrieu (Service de pharmacologie médicale et clinique, CHU Toulouse), Pierre-Olivier Girodet (CIC 0005, Bordeaux), Marcel Goldberg (Inserm U687-UVSQ), Bernard Laumon (Ifsttar), Dominique Lauque (CHU Toulouse), Nathalie Lecoules (CHU Toulouse), Laurence Memes (CIC 0005, Bordeaux), Louis Merle (CHU Limoges), Jean-Louis Montastruc (Service de pharmacologie médicale et clinique, CRPV, Inserm U1027, Université de Toulouse, CHU Toulouse), Pernelle Noize (Inserm U657), Nathalie Orsoni (CHU Limoges), Antoine Pariente (Inserm U657, CIC 0005, Bordeaux), Régis Ribéreau-Gayon (CHU Bordeaux), Louis-Rachid Salmi (Inserm U897, CHU Bordeaux) Frantz Thiessard (LESIM). We acknowledge the French National Health Insurance (CNAMTS), the Inter-Departmental Observatory on Road Safety (ONISR) and Agira-TransPV for providing healthcare and road traffic crash data, as well as the public health Research Federative Institute (IFR 99).

The CESIR-A project was funded by the Afssaps, the French National Research Agency (ANR, DAA n 0766CO204), the French Medical Research Foundation (Equipe FRM), the French Direction Générale de la Santé (DGS) and the French National Medical Research Institute (Equipe INSERM). Employees of Afssaps participated in data collection, interpretation and review of the manuscript. 


\section{REFERENCES}

1. Hansotia P, Broste SK. The effect of epilepsy or diabetes mellitus on the risk of automobile accidents. N Engl J Med. Jan 3 1991;324(1):22-26.

2. Lings S. Increased driving accident frequency in Danish patients with epilepsy. Neurology. Aug 14 2001;57(3):435-439.

3. Taylor J, Chadwick D, Johnson T. Risk of accidents in drivers with epilepsy. $J$ Neurol Neurosurg Psychiatry. Jun 1996;60(6):621-627.

4. Kwon C, Liu M, Quan H, Thoo V, Wiebe S, Jette N. Motor vehicle accidents, suicides, and assaults in epilepsy: A population-based study. Neurology. 2011;76(9):801-806.

5. Yatham LN. Newer anticonvulsants in the treatment of bipolar disorder. $J$ Clin Psychiatry. 2004;65 Suppl 10:28-35.

6. Mula M, Pini S, Cassano GB. The role of anticonvulsant drugs in anxiety disorders: a critical review of the evidence. J Clin Psychopharmacol. Jun 2007;27(3):263-272.

7. Kwan P, Brodie MJ. Neuropsychological effects of epilepsy and antiepileptic drugs. Lancet. Jan 20 2001;357(9251):216-222.

8. Aldenkamp AP, De Krom M, Reijs R. Newer antiepileptic drugs and cognitive issues. Epilepsia. 2003;44 Suppl 4:21-29.

9. Sabers A, Gram L. Newer anticonvulsants: comparative review of drug interactions and adverse effects. Drugs. Jul 2000;60(1):23-33.

10. Hansotia P, Broste SK. Epilepsy and traffic safety. Epilepsia. Sep-Oct 1993;34(5):852-858.

11. Krauss GL, Krumholz A, Carter RC, Li G, Kaplan P. Risk factors for seizure-related motor vehicle crashes in patients with epilepsy. Neurology. Apr 22 1999;52(7):13241329.

12. Orriols L, Delorme B, Gadegbeku B, et al. On behalf of the CESIR research group. Prescribed medicines and the risk of road traffic crashes: a French registry-based study. Plos Medicine. 2010;7(11):e1000366. doi:1000310.1001371/journal.pmed.1000366.

13. Haute Autorité de Santé. Epilepsies graves. Guide-Affections de Longue Durée. 2007.

14. Castot A, Delorme B and the Working Group "Medicinal products and driving". Medicinal products and driving: how to assess the risk? P2T Congress Marseille 2009. Abstract $n^{\circ} 481$.

15. Arrêté du 8 août 2008 pris pour l'application de l'article R. 5121-139 du code de la santé publique et relatif à l'apposition d'un pictogramme sur le conditionnement extérieur de certains médicaments et produits

16. Afssaps. Medicinal Products and Driving. Available online at http://www.afssaps.fr/var/afssaps_site/storage/original/application/e5f2e48d5344bcfef 6ca865ac63e7c3d.pdf (Accessed 29 August 2011). 2009.

17. Robertson MD, Drummer $\mathrm{OH}$. Responsibility analysis: a methodology to study the effects of drugs in driving. Accid Anal Prev. Apr 1994;26(2):243-247.

18. Laumon B, Gadegbeku B, Martin JL, Biecheler MB. Cannabis intoxication and fatal road crashes in France: population based case-control study. BMJ. Dec 10 2005;331(7529):1371.

19. Maclure M. The case-crossover design: a method for studying transient effects on the risk of acute events. Am J Epidemiol. Jan 15 1991;133(2):144-153.

20. Gastaut H, Zifkin BG. The risk of automobile accidents with seizures occurring while driving: relation to seizure type. Neurology. Oct 1987;37(10):1613-1616. 
21. Beaussart M, Beaussart-Defaye J, Lamiaux JM, Grubar JC. Epileptic drivers--a study of 1,089 patients. Med Law. 1997;16(2):295-306.

22. Tomson T, Beghi E, Sundqvist A, Johannessen SI. Medical risks in epilepsy: a review with focus on physical injuries, mortality, traffic accidents and their prevention. Epilepsy Res. Jun 2004;60(1):1-16.

23. van der Lugt PJ. Traffic accidents caused by epilepsy. Epilepsia. Dec 1975;16(5):747751. 
Table 1. Exposure to antiepileptics on the day of the crash according to characteristics of drivers and accidents

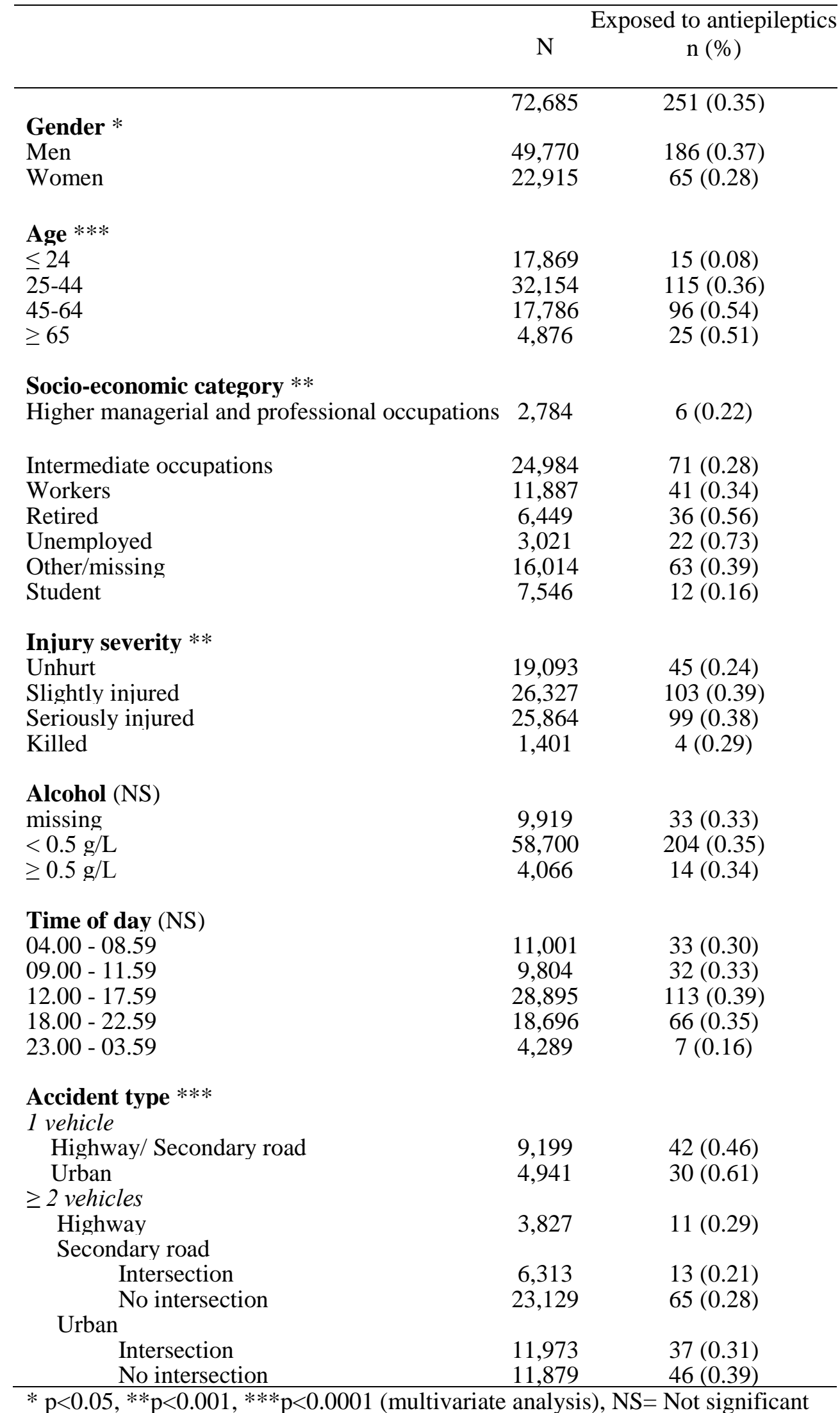


Table 2. Odds ratios for responsible road traffic crashes in users of antiepileptics by generation

\begin{tabular}{|c|c|c|c|}
\hline Antiepileptics & $\mathrm{n}$ & OR $[95 \% \mathrm{CI}]^{\mathrm{a}}$ & OR $[95 \% \mathrm{CI}]^{\mathrm{b}}$ \\
\hline All & 251 & $1.69[1.31-2.18]^{* * *}$ & $1.74[1.29-2.34]^{* *}$ \\
\hline 1st generation ${ }^{\mathrm{c}}$ & 71 & 1.00 [0.63-1.59] & $0.91[0.53-1.56]$ \\
\hline 2nd generation ${ }^{d}$ & 167 & $2.15[1.56-2.97]^{* * *}$ & $2.10[1.45-3.03]^{* * *}$ \\
\hline 3rd generation ${ }^{e}$ & 34 & $3.01[1.40-6.44]^{*}$ & 3.05 [1.15-8.08]* \\
\hline
\end{tabular}

Reference: not exposed to medicines considered

${ }^{a}$ Crude odds ratios

${ }^{\mathrm{b}}$ Odds ratios adjusted for age, gender, socioeconomic category, month, time of day, location, vehicle type, alcohol level, injury severity, concomitant exposure, severe epilepsy and long-term chronic diseases

${ }^{\mathrm{c}}$ Phenobarbital and phenytoin

${ }^{\mathrm{d}}$ Valproic acid and ethosuximide

${ }^{\text {e}}$ Vigabatrin, tiagabin, levitiracetam, zonisamide and lacosamide

${ }^{*} \mathrm{p}<0.05,{ }^{* *} \mathrm{p}<0.001,{ }^{* * *} \mathrm{p}<0.0001$ 